\title{
«Аршин впереди, а штык позади»: особенности складывания этнокультурного ландшафта Тувы в XIX - начале XX в.
}

\author{
Алена А. Стороженко \\ Тувинский государственный университет, Российская Федерация
}

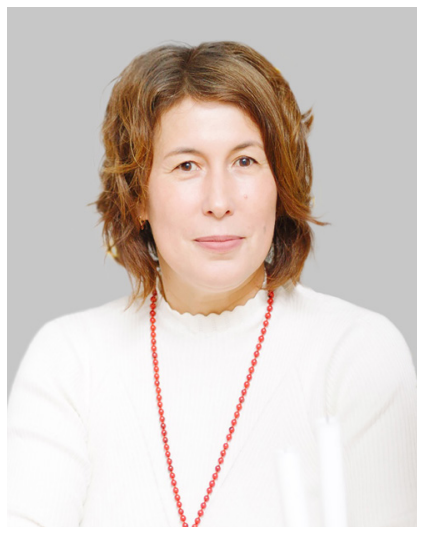

В статье рассматриваются основные тенденции складывания этнокультурного ландшафта Тувы в XIX - начале XX в. сквозь призму взаимных русско-тувинских репрезентаций. Анализируется роль старообрядиев в этом процессе как первопроходцев, рассматриваются особенности их конфессиональных переселений и влияния хозяйственной деятельности на конструирование этнокультурных сообществ Тувы. Общеизвестный факт о решающем влиянии староверов в межкультурном взаимодействии пришлого русского населения и тувинцев как аборигенного народа верифицируется анализом традиций, различных форм взаимовлияний, стереотипов, заимствований, обменов, социальных связей, нашедших отражение во внутренних и внешних презентациях.

Приводятся новые подробности первоначального заселения Тувы русскими переселенцами, основания новых населенных пунктов, взаимоотношений с местным населением. Это дает возможность выявить основные траектории сохранения и развития традиционной культуры русских в контексте этноконфессиональной истории региона. Указанные процессы анализируются на основе неопубликованных воспоминаний русских старожилов, полевых материалов автора, опубликованных тувинских фольклорных материалах, свидетельств иностранных путешественников, чиновников, ученых.

Варианты взаимных репрезентаций этноконфессиональных групп Тувы рассмотрены в контексте проблем устойчивости этноконфессиональных групп Ф. Барта, с учетом того факта, что культурные различия могут сохраняться вопреки межэтническим контактам и взаимосвязям. Впервые комплексно проанализированы образы «своего» и «чужого» в этнокультурной картине мира, отраженные в фольклорных материалах и устных нарративах.

Ключевые слова: Тува; этнокультурный ландшафт; конфессиональное пространство; староверы; старообрядцы; тувинцы; русские Тувы; этническая граница; взаимная репрезентация; этноконфессиональная группа

Стороженко Алена Александровна - кандидат исторических наук, доцент кафедры Отечественной истории Тувинского государственного университета. Адрес: 667000, Россия, г. Кызыл, ул. Ленина, д. 5. Тел.: +7 (394) 222-218-89. Эл. адрес: alstorozhenko@yandex.ru

STOROZHENKO, Alyona Aleksandrovna, Candidate of History, Associate Professor, Department of Russian History, Tuvan State University. Postal address: 5 Lenina St., 667000 Kyzyl, Russian Federation. Tel.: +7 (394) 222-218-89. Email: alstorozhenko@yandex. ru

ORCID ID: 0000-0001-9986-8966 


\title{
«The arshin first, the bayonet follows": the transformation of ethnocultural landscape in $19^{\text {th }}$ and early $20^{\text {th }}$ century Tuva
}

\author{
Alyona A. Storozhenko \\ Tuvan State University, Russian Federation
}

\begin{abstract}
The article examines the main tendencies of building a new ethnocultural landscape in Tuva during the 19th and early 20th century - a process seen through the lens of Russian-Tuvan interrelations, with Old Believers acting as pioneers. The author looks at their confessional migrations and the influence their household economy had on the construction of Tuva's ethnocultural communities. The widely known fact that Old Believers played the key role in the intercultural exchange between newly-arrived Russians and aboriginal Tuvans can be proved by analyzing traditions, various forms of interaction, stereotypes, borrowings, exchanges and social connections which appear both externally and internally.

The article also provides new details of how Russian settlers first appeared in Tuva, founded new settlements of their own and built relations with the local population. This helped us trace the major trajectories for preserving and developing traditional culture of the Russians within the general context of the region's ethnoconfessional history. The author examines these processes in the light of unpublished memoirs by Russian old-timers, published materials of Tuvan folklore, evidence from foreign travelers, officials and scholars, and of field materials collected by the author.

Versions of mutual representations by ethnoconfessional groups are examined here in the context of their sustainability as theorized by Fredrik Barth - given the fact that cultural difference can be preserved even despite interethnic contacts and interrelations. For the first time, the article provides the notions of the "own" vs "alien" in the ethnocultural world view which appear in folklore materials and oral narratives.
\end{abstract}

Keywords: Tuva; ethnocultural landscape; confessional space; Old Believers; Tuvans; Russians in Tuva; ethnic boundary; mutual representation; ethnoconfessional group

For citation:
Storozhenko A. A. «Arshin vperedi, a shtyk pozadi»: osobennosti skladyvaniia etnokul'turnogo landshafta Tuvy v XIX -
nachale XX v. [«The arshin first, the bayonet follows": the transformation of ethnocultural landscape in $19^{\text {th }}$ and early
$20^{\text {th }}$ century Tuva]. New Research of Tuva, 2021, no. 3, pp. 49-60. DOI: https://www.doi.org/10.25178/nit.2021.3.4

\section{Введение}

Тува как место встречи и взаимодействия цивилизаций, конфессий, этносов и культурных групп является уникальной исследовательской площадкой. Сложившееся сложное ее социокультурное пространство состоит из представителей самых разных этносов - тувинцев, русских, хакасов, татар, немцев, евреев, украинцев, киргизов, монголов и других народов, являющихся носителями тюркских, славянских, финно-угорских языков, а также буддийского, христианского, языческого вероисповедания. Весь этот сплав культур складывался веками, пройдя непростой путь цивилизационного развития.

Старообрядцы в настоящее время являются органичной частью этнокультурного ландшафта Тувы, важной составляющей своеобразного регионального бренда. Перечисляя очевидные отличия Тувы от прочих, как минимум, сибирских регионов, местные жители нередко упоминают поселения староверов в Каа-Хемском кожууне. Признание особой староверческой этноконфессиональной идентичности, образа жизни последователей старой веры - позволяет живущим в Туве и тувинцам, и русским рефлексировать на тему уникальности этого социокультурного явления. При этом значительное число русских являются прямыми потомками староверов разных субконфессиональных групп и общин. Они сохраняют историческую память и выражается это в формулах: «моя бабушка была староверка», «мою маму крестили по-старому», «у нас в деревне жили староверы». Тувинцы в целом уважительно отзываются о старообрядцах, подчеркивая их хозяйственность, домовитость, правда при этом слабо представляя конфессиональные отличия от последователей официального православия, не считая их решающими. 
Анализу форм взаимодействия русских в целом и старообрядцев в частности с тувинцами и другими этнокультурными группами Тувы, а также осмыслению категорий, с помощью которых в научном и общественном дискурсах формировались определённые образы старообрядцев и посвящена настоящая статья. Особое внимание будет уделено проблемам взаимных репрезентаций восприятия и отражения этнокультурных сообществ региона, преимущественно старообрядцев как представителей русской культуры в целом и тувинцев как аборигенного населения в архивных, полевых материалах, а также в фольклорных источниках и свидетельствах путешественников, чиновников и ученых. Устойчивость этнических границ, исторически продемонстрированная староверами и тувинцами, является важным ключом к пониманию природы культурного многообразия.

\section{Обзор научной литературы, источниковая и методическая база исследования}

Как мы уже ранее писали (Стороженко, 2015, 2019а), история переселения старообрядцев в Туву, их внутренней структуры, культуры и религиозной жизни давно привлекает внимание исследователей. Изучение переселенческих вопросов неизбежно вызывает, как минимум, упоминание о роли старообрядческого населения в этом процессе, ведь в большинстве сибирских регионов староверы были первопроходцами и первыми покорителями новых земель (Кон, 2007ab; Маслов, 2007; Дулов, 1956; Мамсик, 1982; Татаринцева, 2006 и др. $\left.{ }^{1}\right)$.

Вопросы русско-тувинских отношений рассмотрены во многих работах, но для настоящего исследования наиболее ценными являются основные положения, сформулированные в монографиях Г. Ф. Балакиной, 3. В. Анайбан (Балакина, Анайбан, 1995), Г. Ф. Балакиной (Балакина, 1998), Ч. К. Ламажаa (Ламажаa, 2018), М. П. Татаринцевой (Татаринцева, 2006, 2018), М. П. Татаринцевой и Н. М. Моллерова (Татаринцева, Моллеров, 2016).

Вопросам историко-этнографического изучения тувинской литературы посвящена фундаментальная монография Г. Н. Курбатского «Тувинцы в своем фольклоре» (Курбатский, 2001), содержащая важный анализ тувинско-русских фольклорных связей и, что более важно, отражения образов русских и их быта в образцах тувинской литературы, собранных Н. Ф. Катановым (Катанов, 2011) и опубликованным В. В. Радловым (Радлов, 1907).

Исследования по истории и культуре старообрядчества как фронтирной части русского этноса, в том числе переселившейся в Туву еще в период ее заграничного статуса, наиболее серьезно повлиявшая на формирование гетеростереотипов в отношении русских в целом со стороны тувинцев, также важны для понимания общего процесса складывания этнокультурного ландшафта (Покровский, Зольникова, 2002; Татаринцева, 2006; Рыговский, 2018).

Существует несколько вариантов периодизаций русско-тувинского взаимодействия и переселения русских в Туву (Кон, 2007а; Дулов, 1956; История Тувы, 2001), но большая их часть в качестве основных категорий различения этапов берет переселенческую активность и политико-экономические факторы. Вариант, предложенный Ч. К. Ламажаа, не отказываясь от учета политического и экономического контекста, в основе имеет этнокультурные факторы: 1) экономическое, бытовое сотрудничество; 2) вхождение в российские цивилизационные процессы; 3) дихотомия «Старший - Младший» (Ламажаа, 2018: 119-128). Данный подход может считаться наиболее продуктивным для выяснения факторов, влиявших на формирование авто- и гетеростереотипов русских и тувинцев в Туве.

Методической основой исследования послужила концепция этничности Ф. Барта, согласно которой «...необходимым условием существования категориальных этнических различий является не отсутствие мобильности, контактов и информации, а наличие социальных процессов исключения и включения, посредством которых дифференциальные признаки продолжают сохраняться... и ...существование этнических различий не предполагает взаимонеприятия и отсутствие социального взаимодействия, но, напротив, нередко становится тем фундаментом, на котором возводятся все социальные системы» (Барт, 2006: 10). Продолженное в исследованиях О. В. Беловой исследование процесса формирования образа «чужого» на основе стереотипов, сформированных вековой мифологической традицией, динамично развивающейся между двумя полюсами - отторжения и толерантности (Белова, 2005: 7) стало методологическим ориентиром настоящей статьи.

${ }^{1}$ См. также: Путилов Н. А. Усинский край // Енисейские епархиальные ведомости. 1885, № 1, 5, 9, 12, 16, 19-20. 
Источниковая база нашего исследования разнообразна и ее состав обусловлен предметом исследования, связанного с необходимостью учета не столько официальных позиций, столько репрезентации народного взгляда, отраженного в устных нарративах, преимущественно русских переселенцев и их потомков об особенностях первоначального процесса переселения и складывающихся взаимоотношениях с тувинцами. Они хранятся в Рукописном фонде Национального музея им. Алдан-Маадыр Республики Тыва (далее - РФ НМ РТ), преимущественно в фонде П. А. Черкашина и представляют собой рукописные и машинописные копии интервью, взятых П. А. Черкашиным в 1950-1960-х годах у русских жителей Тувы (РФ НМ РТ, фонд П. А. Черкашина).

\section{Этноконфессиональная ситуация}

В 1911 г. начальник Усинского пограничного округа, штабс-капитан А. Х. Чакиров подал на имя Иркутского генерал-губернатора секретную записку «О положении “Урянха” за последнее трехлетие 1909-1911 гг.» (РФ НМ РТ. Фонд П. А. Черкашина. Папка № 9 «Из дела чиновника по дипломатической части»). В ней он подробнейшим образом рассмотрел историю русского переселения в Урянхай, дал сравнительный анализ политики русских и китайских торговцев, особенности хозяйственной деятельности и пришел к заключению, что те русские, которые вредят благосостоянию урянхов, должны быть выселены. Но есть и немало русских, подчеркивал Александр Христофорович, торговцев, крестьян, которые

«...не обращая внимания на все трудности, на все мытарства, препятствия, лишения преследуя ли цели наживы, идя ли искать потерянное - сделали по силе возможности свое (дело. - вероятно пропущено слово. - А. С.) и потому вполне справедливо будет заметку свою закончить вступлением же, но с маленькой перестановкой слов, а именно - “Аршин впереди, а штык позади”. Аршин свое почти сделал. Дело за штыком - плюс за рублем» (там же: л. 15; выделено в цитате нами. - А. С.).

Чиновник таким образом вольно-невольно одновременно подвел итог, а также пророчески определил дальнейший ход развития событий.

С одной стороны, был подчеркнут тот самый мирный, бытовой характер этапа «Аршина» - первоначального проникновения русских в Туву, когда главным образом переселенцам была нужна земля, пастбища, угодья, место для хозяйствования и свобода. Не было задачи отобрать у тувинцев землю и ресурсы, истребить их как этнос. Этап «Штыка» должен был, по мнению Чакирова, наступить в борьбе с Китаем за пограничную, буферную территорию, а «Рубль» стоило применить для того, чтобы «...дать хошунам и сумо ссуду, для полной расплаты с торговцами китайцами и уплаты податей... На нас лежит долг поднять благосостояние урянхов, так как от благосостояния Урянхая выиграет ни одна русская торговля... но и русское дело на границе с Китаем» (там же: л. 14). Именно в этом направлении в целом и развивались дальнейшие события.

Первые контакты представителей двух совершенно разных этносов, культур не были однозначно комплементарными. Первые попытки переселиться, начавшиеся еще в 30-е годы XIX века алтайскими крестьянами (Мамсик, 1982) и ставшие постоянными в 1860-е годы, привели к закреплению сначала приисков, торговых факторий, охотничьих заимок, а потом и целых земледельческих поселков.

Факт первой попытки переселения давно стал общим местом во всех исследованиях, затрагивающих тот или иной аспект истории переселений старообрядцев и русских в Туву. Подробности этой истории неоднократно описаны в литературе (Кон, 2007а; Дулов, 1956; История Тувы, 2001). Решение обосноваться в Уюкской долине, на территории, находившейся в подчинении Цинской империи, выглядит одновременно и продуманным и не очень. Конечно, старообрядцы знали, что это заграничная территория, но слабость административно-управленческой системы китайских властей, очевидно, давала надежду на возможное закрепление.

Впервые упоминание об этом случае встречается в работе Ф. Я. Кона «Усинский край» (Кон, 2007а: 280-281), где он, опираясь на несохранившийся архив Усинского пограничного управления, подробно цитирует предписание Минусинского окружного исправника, направленное 9 февраля 1868 г. в Шушенское волостное правление. В нем, в частности, говорится, что 27 октября 1867 г. Главное управление Восточной Сибири уже знало о «...переходе русских, в числе 30 человек, границы около Хонин-Даба и о постройке в китайских пределах домов...» (там же: 280-281). 21 января 1868 г. был составлен «Именной список лицам, заселяющимся на местности на р. Уюку, впадающей с правой стороны», в котором наряду с 29 уймонскими инородцами Мамонтовыми, Огневыми, Блиновыми, Бочкаревыми указано 
и семейство Никиты Вавилина. Всего в данном пофамильном «Списке» значится 34 человека ${ }^{1}$ (ГАИО, ф. 24, оп. 10, картон 1667, д. 285, л. 4-4 об.).

Скорее всего дело обстояло так, как описывал потомок староверов Бочкарев в своих воспоминаниях в середине XX века. Староверы охотничали и

«...наткнулись на этот Ус внезапно. Тут одни тувинцы жили, сойотами их тогда называли. Их сойоты окружили, дескать, что за люди? Они не ведали, что за русский народ. Окружили. Начальник был Янга, ответственный начальник в Усинске. И вот они их связали этих людей русских и начали спрашивать. Один тувинец подходит и говорит, что эти люди хороши, нужно их отпустить...» (РФ НМ РТ, фонд П. А. Черкашина, л. 14).

Впоследствии, после требования вернуться в российские пределы, Вавилин со своим семейством осел в Верхнеусинском и уже его сыновья и внуки вошли в источники как богатые и влиятельные люди, которым позднее все-таки удалось осесть в Урянхае, обогатиться. Русские переселенцы вспоминали о нем: «Цвет Вавилина (очевидно - Василия Никитича) был черный... его тувинцы звали Кара-Василий (это по-тувински - черный Василий). А Родион Васильевич был рыжий, бороду стриг, хотя и старообрядец был, а Василий Никитич не стриг» (там же: л. 18).

Большинство оставленных свидетельств о жизни Усинско-Урянхайского края на рубеже ХIX и $\mathrm{XX}$ столетия обязательно содержит упоминания Родиона Васильевича Вавилина как человека, хорошо знающего тувинский язык (во время визита в Урянхай иркутского генерал-губернатора Князева он был его переводчиком), пользовавшегося доверием у тувинцев, имевшего влияние в среде русских. Факторий у Вавилина было несколько, работники были нужны.

«У Вавилина на Уюке работники были все больше русские, а тувинцы почему-то не работали, они ленивые к работе, не работали. ... Вот китайцы с сойотами торговали так: обижали сойотов шибко, а чем обижали? Тем, что говорят: бери в долг, бери в долг. Сойот взял в долг, отдавать не отдает, ему нечего отдать, а в долг забрал» (РФ НМ РТ, фонд П. А. Черкашина, л. 15).

Несмотря на очевидный грабительский характер долговой торговли тувинцы нуждались в русских товарах, лишаясь порой главного богатства - скота.

«Если не придут сюда русские,

то откуда явится красная неизносимая бязь?

Если не придут сюда Казаки,

то откуда явится варимый чай твой?» (Радлов, 1907: 101).

«О, брат мой, пришел русский и

узнал моего голубо-солового коня!

О брат мой, пришел Казак и

угнал моего вороно-солового коня» (там же: 97).

В «Песнях», записанных Н. Ф. Катановым на разных торговых заведениях и заимках Сафьяновых, Бяковых, Горбуновых и других русских переселенцев в августе 1889 г., ярко выражены переживания тувинцев о захвате русскими лучших земель, об утрате влияния в своей земле:

«Островок с узким бродом,

не стал ли уже местом жительства русского?

Откровенная, чернобровая Сазымай,

не стала ли уже женой русского?» (там же: 104).

«Чер-Чарык, состоящий из великолепной степи

стал местом жительства русских!

Сабыячык, велоколепная и чернобровая,

стала женой русского!» (там же: 145).

Подобные сюжеты проходят «красной нитью» через все полевые записи Н. Ф. Катанова. Зачастую символизация территориального влияния переплетается в тувинских текстах с гендерными вопросами.

«Не прошла ли русская дорога по Чадане,

так уже испещренной дорогами?

${ }^{1}$ Подробнее об этой истории: Стороженко, 2019b. 
Девиц милых и чернобровых

не взяли-ли уже русские в жены?» (там же: 93).

В русском фольклоре, конкретно - в частушках, собранных М. П. Татаринцевой (Татаринцева, 2009; Татаринцева, Моллеров, 2016: 81), также отразились личностные связи, возможности заключения браков / наличия межнациональных любовных связей, но это уже взгляд со стороны пришлого населения. Не часто, но тувинцы женились на девушках из старообрядческой среды, как правило, с принятием веры молодой жены ${ }^{1}$.

«Давай миленький, покурим.

Я не староверочка.

Я привыкла к табаку,

Молодая девочка» (там же: 17).

В последнем примере старообрядцев резко выделяют в общей массе русских в Туве, есть указание на особенности их системы запретов и ограничений - неприятие табакокурения, причем упор делается именно на молодой возраст.

Как правило, при анализе основных векторов развития русско-тувинских отношений, взаимных репрезентаций, оценок применительно к периоду XIX - начала XX в., зачастую подчеркивается грабительский характер русско-тувинской долговой торговли, приводятся примеры быстрого обогащения русских торговцев - Веселкова, Сафьяновых, Вильнера, Медведевых, Черневича, Вавилина и других. Но при этом, как бы не учитывается тот факт, что «капиталистых» переселенцев было немного, больше было таких же середняков и бедняков, которыми было и подавляющее большинство тувинцев.

Показательна история переселения и обустройства семейства Сидоровых - муж, жена, три сына и дочь - выехали из Тобольской губернии в 1909 г. через Минусинск в Усинское, нанялись в работники уже к богачу Родиону Вавилину.

«В то время у богача Вавилина в Урянхае было 7 экономий, но главная была по Уюку. Вавилин имел широкую торговлю с урянхами. Его доверенные торговали товарами, скупали: быков, баранов, пушнину, кожи всех видов...Землю обрабатывали русские и урянхи батраки за низкую месячную оплату 6 и 8 рублей в месяц - это хорошим рабочим. ...Мой муж Андрей рассчитался от Вавилина, его сговорил Усинский крестьянин Спрыгин Пимен: что Андрей будет жить в работниках, вот в Урянхай приглашают ихние нойоны, чтоб русских больше заезжало в Урянхай сеять хлеб, косить сено чтоб урянхи учились у русских. Проводить из речек канавы и орошать землю. Я поселился на речку Брень, по Малому Енисею. Вот поедем ко мне заготовишь сена, спаши землю хоть одну десятину, я дам лошадей. У нас свой один конь крепкий хороший татарский степняк годов 9. Вот мой муж и уехал» (РФ НМ РТ, фонд П. А. Черкашина, рассказ Феклы Степановны Сидоровой, л. 33).

Но по приезду на Брень его встретил Хлебников Аким и предложил поселиться выше по Енисею на Бельбее, где было только 3 двора.

«Он съездил к нояну на Брень, где проживал владыка всего Малого Енисея. Получил от него бумагу на поселение на Бельбей. Это нужно для местного тарги этой степи. Тарга - это власть чина старосты. Жили они в юрте на левой стороне Енисея, жили очень бедно, скота своего было мало, а люди все были пастухами нойона, который сам не знал счета своего скота» (там же: л. 34-35).

В 1912 г. они перебрались в Урянхай, взяли в Бегреде заграничный билет у Чакирова. По пути им пришлось остановиться на Усть-Брени в многодетной семье (7 сыновей и дочь) Пимена Евграфовича Спрыгина. «Пока мы были приходило много тувинцев, она каждого угощали и чаем и хлебом, все до 7-летнего говорили на урянхайском языке, за исключением молодухи» (там же: л. 38).

Заимка Пимена Евграфовича Спрыгина долго была форпостом русского освоения на Малом Енисее. В воспоминаниях его сына Минея Пименовича описано то, как эта семья сумела закрепиться в 1909 г., переселившись из Усинска:

«...отыскал нойона и стал проситься на жительство, рекомендуя свою специальность слесарь кузнец. В то время было очень трудно заехать и поселиться, местные тувинцы не пускали русских. Тогда ноян спросил у купцов Шипилина и Ведерникова, которые одобрили о Спрыгине Пимене, что он неплохой человек, хороший слесарь, исправляет ружья, которые не попадают в цель, нарезает винт внутри ствола и т. д. Тогда ноян разрешил Пимену Евграфовичу жить на устье Брени» (РФ НМ РТ, фонд П. А. Черкашина, п. 38. М. П. Спрыгин «Мой отец Пимен Спрыгин. Воспоминания», лл. 3-5).

${ }^{1}$ Самым известным случаем является женитьба С. К. Тока на староверке. 
Это привело к появлению тувинских песен, в которых этот процесс хозяйственного освоения и территориального расселения русских выглядел уже как попустительство и слабость со стороны салджакского нойона:

«О ленивая толпа салджаков,

отдавшая мое кочевье у подошвы Булук.

О щедрая толпа салджаков,

отдавшая мое кочевье у подошвы Кербис!» (Радлов, 1907: 28).

В результате интенсивного хозяйственного освоения переселенцами появились новые типы оседлых поселений: торговые фактории, прииски, маральники, усадьбы, мельницы, рыболовные избушки, зимовья. К 1909 г. в Урянхайском и Усинском крае было 148 русских населенных пунктов, из них -6 деревень, 12 поселков, 19 приисков и 112 заимок, в которых проживало более 6750 жителей (подсчитано по: «Ведомости русских поселений в пределах Урянхайского края и Усинского округа по сведениям 1907-1909 гг.», см.: Родевич, 2007: 474-499).

Старообрядцы проникали в Туву разными путями: и через Монголию с Алтая и через Тоджу по Амыльской тропе, по долине р. Ус, напрямую в Чаа-Холь, чуть позднее - по Усинскому тракту и постепенно освоили все пригодные зоны для ведения комплексного хозяйства - земледелия, охоты, животноводства, огородничества, собирательства.

\section{Образ «цужого»}

Народные традиции, культура, вера являются той основой, опираясь на которую, этнос пытается осмыслить свою идентичность, свое место в истории. Как тонко подметила О. В. Белова: «Нарисовать для себя портрет “чужого” - соседа, чужеземца, иноверца - значит во многом осознать себя самого, свою уникальность и своеобразие» (Белова, 2005: 7). В нашем случае категория «чужого» также включает в себя «...общее знание относительно религии и быта, обрядов и ритуалов, языка и верований этнических соседей» (там же: 8). Опираясь на работы Я. Быстроня, Л. Стомма и Я. Ястрежбски, О. В. Белова предлагает выделить ряд ключевых позиций, по которым определяется «чужой» среди «своих»: внешность, отсутствие души, сверхъестественные свойства, «неправильное» поведение, язык (там же: 10). В целом, данный набор признаков может быть признан в качестве основы для создания некоего общего портрета, выработанного в народном сознании в процессе русско-тувинского межкультурного взаимодействия в рамках семантической категории «свой - чужой».

Внешний облик, особенно в ситуации цивилизационной встречи тюрков и славян, был наиболее ярким отличительным признаком образа «чужого», особенно на начальном этапе межкультурного взаимодействия. Особенности природно-климатических условий «принимающей» территории - Тувы постепенно убедили русских переселенцев перенять традиционную одежду тувинцев, очевидно, как наиболее удобную и практичную. Самым ярким примером является фотография детей и племянников Родиона Васильевича Вавилина, сделанная на крыльце его дома в с. Верхне-Усинском (рис. 1). На девочках надеты традиционные тувинские тоны - зимние пальто, выполненные в соответствии с традиционными приемами пошива тувинской верхней одежды и национальным орнаментом, возможно из традиционной материи. На мальчиках - зимние тоны-тулупы, тоже сшиты как традиционная тувинская верхняя мужская одежда, с застежкой на «мужскую» сторону из овчины.

В народной картине мира второй половины XIX века в самом начале тесного межкультурного взаимодействия двух этнических групп, максимально «работали» представления об отсутствии души у «чужого», равно у русских, и у тувинцев. По свидетельству православного миссионера Н. А. Путилова «Название собака как бы усвоилось между русскими в разговорах их о сойотах» (Путилов, 1914: 35). Аналогичное отношение демонстрирует и тувинское сознание: «Когда русский приходит к тоджинцу, тот, делится с другими этой новостью, говоря: «Я думал, что пришел человек, а это русский» (Кон, 2007b: 511), что, по мнению Г. Н. Курбатского, означало: «...не наш, не соплеменник» (Курбатский, 2001: 31).

Для создания образа «чужого», наделения / приписывания ему определенных признаков требуется достаточное окружение. Единичные контакты не дают возможности идентификации далее, чем язык, внешность, иногда «неправильное» поведение. Накопление сведений о занятиях, обрядах, верованиях, обычаях шло постепенно, несколько ускорилось во второй половине XIX в. и приняло лавинообразный характер после 1914 г. в связи с хлынувшим потоком переселенцев, заполнившим практически весь вмещающий ландшафт. 


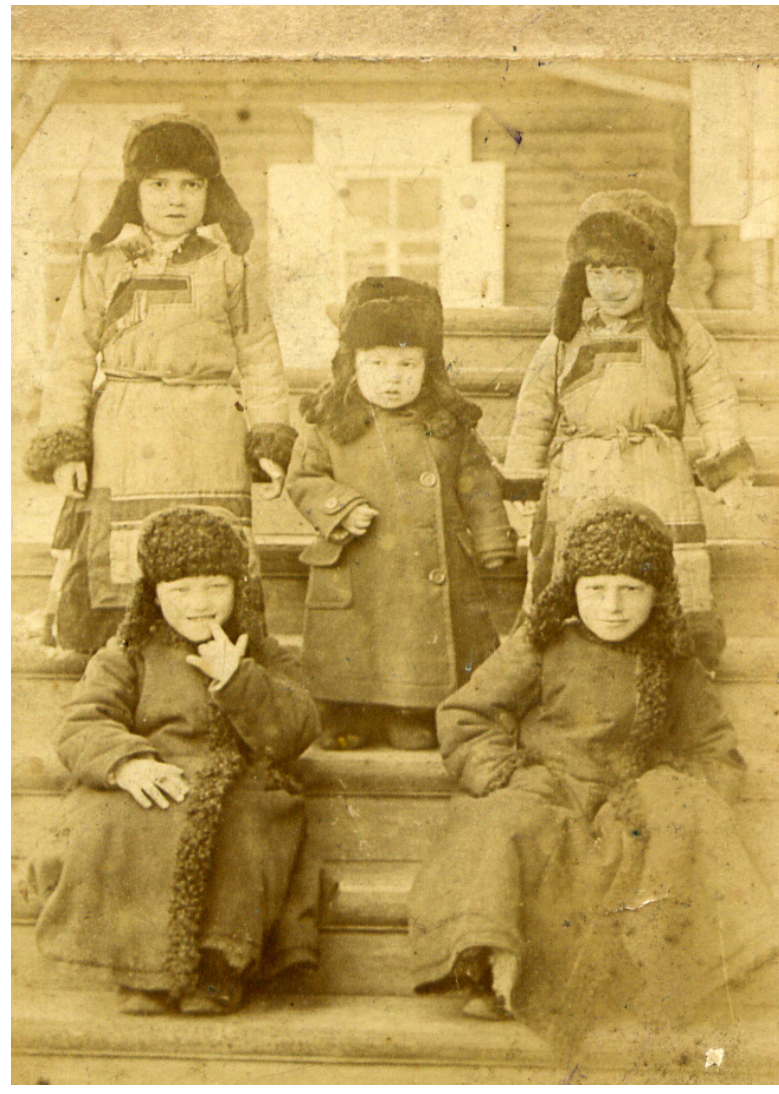

Рис. 1. Семья Родиона Васильевича Вавилина в с. Верхне-Усинском, вторая половина XIX - начало XX в. Фото из личного архива потомков Е. А. Вавилина и Н. В. Вавилиной, г. Новосибирск.

Fig. 1. The family of Rodion Vasilievich Vavilin, Verkhne-Usinskoye village, second half of $19^{\text {th }}$ or early $20^{\text {th }}$ century. Photo from the private collection of E. A. Vavilin and N. V. Vavilina, Novosibirsk.
В воспоминаниях русских переселенцев Малоенисейского - Каа-Хемского района - в середине XX века четко видна социальная дифференциация тувинского общества, особенности «неправильного поведения», других хозяйственных практик.

«Наши урянхи жили очень бедно. Скота у них было мало. Жили в юртах, построенных кругом в наклон палки и покрытом берестом, снятого с берез или лиственницы. Одна только юрта была из войлока, скатанного из овечьей шерсти, а у богатых все из войлока. Юрты большие, внутри юрт посланы шкуры. У богатых медвежьи или китайские ковры, у бедных конская или вовсе ничего. ... Мужчины выполняют домашнюю работу только охота и седло, гонят лошадей, скот, остальное все должна выполнять женщина. Заготовка дров, уход за скотом, уборка навоза, шитье обуви и одежды. Женщина считается полной рабой и бесправной. Зимой скот всю зиму ходит, разгребает ногами снег и добывает себе корм. Сено не косят. Даже у них нечем было косить. Резали траву ножами, крутили длинные веревки и вешали на сучья деревьев и в марте, когда нарождается молодняк, достают и вяжут пучок...» (РФ НМ РТ, фонд П.А. Черкашина, рассказ Феклы Степановны Сидоровой, л. 42).

Показательна постоянная отсылка - «наши урянхи», подчеркивающая стремление к стиранию этнических границ во внешней рефлексии внутренних переживаний ${ }^{1}$.

«Сын Степан ...дружил с парнями урянхами. Особенно у него был друг бедный урянх Подугечик и другие наши урянхи, были очень хорошие. Воровством не занимались, жили мы с урянхами дружно.....Марк, когда жил у Михайлова, то у него жило много урянхов. Один из них был маленький, который спал с Марком. Отводил его в баню, мыл и начинал одевать, спали на конюховской. Мальчику было лет 10. Звали его Тока Салчак. Он хорошо говорил по-русски. Марк учил его русскому алфавиту и писать буквы. Ему все это давалось легко. Научился даже играть на гармошке и учился плясать и петь русские песни. Второй такой же был Инзак - сирота скиталец. Тоже был способен, говорил по-русски и учился писать. Третий мальчик был в Бельбее, звали его Вангур (очевидно - Увангур. - A. C.)» (там же: л. 44; выделено нами. - A. С.).

Подобные картины этнической и социальной близости весьма характерны для среды давнего дисперсного расселения русских в тувинской среде - Пий-Хемского, Каа-Хемского, Тоджинского, Тандинского районов.

К концу XX столетия в этнокультурном ландшафте Тувы сформировался устойчивый набор авто- и гетеростереотипов. Исчезли из перечня признаков как важные - внешность, душа. Остались - «неправильное» поведение и язык.

Зато взаимные репрезентации свойств характера, мало изменившиеся за целое столетие, стали более детальными. Тувинцы, наряду с положительными качествами русских (гостеприимные, открытые, простые, трудолюбивые, энергичные) отмечали в большинстве своем такие отрицательные качества, как лицемерие, хитрость, зависть, властолюбие. Положительными качествами у тувинцев, по мнению русских, являются гостеприимство, открытость, простота, почтительность со старшими; отрицательными - леность, безответственность, скрытность. При этом себя русские воспринимают как терпеливых, миролюбивых, но лицемерных, хитрых, непрактичных, безответственных. Тувинцы,

${ }^{1}$ Подобные высказывания встречались нам в этносоциальной экспедиции 2005 г. в Тоджинском кожууне РТ, когда русские учителя Тоора-Хемской школы во время экспертного интервью постоянно говорили: «наши тувинцы», «наши тоджинцы», имея в виду тувинцев-тоджинцев. 
как наиболее характерные для своей этнической группы, назвали следующие качества: гостеприимные, простые, терпеливые, но и ленивые, непрактичные, скрытные (Балакина, 1998: 84).

\section{Заключение}

Переселение русских старообрядцев на территорию современной Тувы, начавшееся в первой половине XIX века, привело к изменению ее этнокультурного ландшафта. Тувинцы являлись аборигенным народом территории, именовавшейся в течение XIX века и до 1921 г. как Сойотия, Урянхайский край / Урянхай, Усинско-Урянхайский край, Усинский пограничный округ с 1885 г. также включал в себя северные пограничные территории - поселки Уюк и Туран. Именно в этот период русскими и другими переселенцами (хакасами, татарами, евреями) был заложен первый слой поселенческой структуры, намечены ее основные контуры, на карте появились первые населенные пункты - заимки, деревни с русскими названиями.

Свидетельства русских современников событий первой половины XX века, записанные в его середине, есть результат предшествующего этапа интенсивной адаптации русских в иной - «чужой» среде. И они уже дают возможность делать выводы о свойствах характера, поведения. В свою очередь, для тувинцев, продолжительное время просто наблюдавших и слабо сопротивлявшихся русскому заселению, эти «чужие» - русские, преимущественно староверы, а также другие этнокультурные группы дольше и сильнее были непонятны. Это происходило в силу того, что тувинцы были принимающей стороной, имели свои налаженный быт, общественные отношения, хозяйственную систему, в которые русские были вынуждены встраиваться, искать подходы, а также мириться с ограничениями. Это предопределило характер размещения - подальше от тувинских кочевий; направленности внутрирегиональной миграций - в долины, а потом и в верховья рек, в лес. Русские были вынуждены учить тувинский язык, перенимали приемы хозяйствования, одежду, обувь, осваивали обычаи, заключали браки. Непреодолимыми остались: вера, жилище, способы ведения домашнего хозяйства, обычаи, праздники.

Достаточно длительная история русско-тувинского межкультурного взаимодействия не привела к ассимиляции, не случилось масштабной христианизации местного населения, как в некоторых других сибирских регионах. Тувинцы сохранили родной язык, культуру, религиозный комплекс, менталитет, обрядовую практику. Русские сумели адаптироваться в иноконфессиональной, инокультурной среде, оказав значительное влияние на вмещающий ландшафт. Каждая из этих этнических групп сохранила свои существенные культурные отличия, находясь при этом с середины XIX века в постоянном, нарастающем взаимодействии - хозяйственном, социальном, конфессиональном, приводящем к нарушению этнических границ.

\section{Благодарности}

Особую благодарность за ценные и добрые советы, помощь и поддержку, совместное обсуждение идей хочется выразить доктору исторических наук, профессору Одесского национального университета им. Мечникова Пригарину Александру Анатольевичу; доктору исторических наук, профессору Томского государственного университета Дутчак Елене Ерофеевне; а также кандидату филологических наук, ведущему сотруднику сектора истории ТИГПИ при правительстве РТ Татаринцевой Маргарите Петровне.

\section{СПИСОК ЛИТЕРАТУРЫ}

Балакина, Г. Ф., Анайбан, 3. В. (1995) Современная Тува: социокультурные и этнические процессы. Новосибирск : Наука. Сиб. изд. фирма. 137 с.

Балакина, Г. Ф. (1998) Динамика социокультурных реалий в период трансформации // Социально-экономические проблемы Республики Тыва в период трансформации : сборник научных статей / отв. ред. Г. Ф. Балакина. Новосибирск : Изд-во СО РАН. 120 с. С. 75-84.

Барт, Ф. (2006) Введение // Этнические группы и социальные границы. Социальная организация культурных различий / под ред. Ф. Барта. М. : Новое издательство. 200 с. С. 9-49.

Белова, О. В. (2005) Этнокультурные стереотипы в славянской народной традиции. М. : Индрик. 288 с.

Дулов, В. И. (1956) Социально-экономическая история Тувы (XIX - начало XX вв.). М. : Изд-во Академии наук СССР. 608 c. 
История Тувы (2001): в 3 т. 2-е изд., перераб. и доп. / под общ. ред. С. И. Вайнштейна, М. Х. Маннай-оола. Новосибирск : Наука. Т. 1.367 с.

Катанов, Н.Ф. (2011) Очерки Урянхайской земли. Дневник путешествия, исполненного в 1889 году по поручению Императорской Академии наук и Императорского Русского географического общества / отв. ред. К. А. Бичелдей, вступит. сл. и коммент. А. К. Кужугет. Абакан : Кооператив «Журналист». 383 с.

Кон, Ф. Я. (2007а) Усинский край // Урянхай. Тыва дептер. Антология научной и просветительской мысли о древней тувинской земле и ее насельниках, об Урянхае - Танну-Туве, урянхайцах - тувинцах, о древности Тувы / сост. С. К. Шойгу. М. : Слово. Т. 4. 552 с. С. 262-348.

Кон, Ф. Я. (2007b) Экспедиция в Сойотию //Урянхай. Тыва дептер. Антология научной и просветительской мысли о древней тувинской земле и ее насельниках, об Урянхае - Танну-Туве, урянхайцах - тувинцах, о древности Тувы / сост. С. К. Шойгу. М. : Слово. Т. 4. 552 с. С. 348-548.

Курбатский, Г. Н. (2001) Тувинцы в своем фольклоре (историко-этнографические аспекты тувинского фольклора). Кызыл : Тувинское книжное издательство. 464 с.

Ламажаа, Ч. К. (2018) Национальный характер тувинцев. М. ; СПб. : Нестор-История. 240 с.

Маслов, П. П. (2007) Конец Урянхая // Урянхай. Тыва дептер. Антология научной и просветительской мысли о древней тувинской земле и ее насельниках, об Урянхае - Танну-Туве, урянхайцах - тувинцах, о древности Тувы / сост. С. К. Шойгу. М. : Слово. Т. 5.733 с. С. 618-729.

Мамсик, Т. С. (1982) Беловодцы и Беловодье (По материалам следственного дела о побеге 1827-1828 гг.) // Источники по культуре и классовой борьбе феодального периода (Археография и источниковедение Сибири) / отв. ред. Н. Н. Покровский, Е. К. Ромодановская. Новосибирск : Наука. 273 с. С. 135-165.

Покровский, Н. Н., Зольникова, Н. Д. (2002) Староверы-часовенные на востоке России в XVIII-XX вв. : Проблемы творчества и общественного сознания. М. : Памятники исторической мысли. 471 с.

Путилов, Н. А. (1885) Усинский край // Енисейские епархиальные ведомости. № 1, 5, 9, 12, 16, 19-20.

Путилов, Н. А. (1914) Летопись Усинской миссии, находящейся на реке Усу, Енисейской губ., Минусинского округа, Шушенской волости, близ китайской границы // Сибирский архив : журнал истории, археологии, географии и этнографии Сибири, Средней Азии и Дальнего Востока. № 1. Январь. С. 27-40.

Радлов, В. В. (1907) Образцы народной литературы тюркских племён. Ч. ІХ. Наречия урянхайцев (сойотов), абаканских татар и карагасов. Тексты, собранные и переведенные Н. Ф. Катановым. СПб. : б. и. 659 с. С. 1-216.

Родевич, В. М. (2007) Очерк Урянхайского края (Монгольского бассейна реки Енисея) // Урянхай. Тыва дептер. Антология научной и просветительской мысли о древней тувинской земле и ее насельниках, об Урянхае - ТаннуТуве, урянхайцах - тувинцах, о древности Тувы / сост. С. К. Шойгу. М. : Слово. Т. 3. 608 с. С. $244-541$.

Рыговский, Д. С. (2018) «Правило чашки»: гостеприимство старообрядцев в антропологической перспективе // IV Центральноазиатские исторические чтения. Пространство культур: через призму единства и многообразия: сборник материалов Международной научно-практической конференции / под ред. 3. Ю. Доржу, В. М. Дамдынчап, Ю. В. Попкова, А. А. Стороженко. Кызыл : Изд-во ТувГУ. 350 с. С. 172-177.

Стороженко, А. А. (2015) Конфессиональные миграции старообрядцев как канал межкультурного взаимодействия в Центральной Азии в XIX - начале XX в. // Старообрядчество: история и современность, местные традиции, русские и зарубежные связи: Материалы VI Международной научно-практической конференции / науч. ред. А. П. Майоров, отв. ред. С. В. Васильева. Улан-Удэ : Изд-во Бурятского гос. ун-та. 392 с. С. 130-136.

Стороженко, А. А. (2019a) Старообрядческие монастыри «енисейского меридиана» в XX веке: истоки, традиции и современное состояние // Новые исследования Тувы. № 1. C. 4-15. DOI: https://www.doi.org/10.25178/ nit.2019.1.1

Стороженко, А. А. (2019b) С Волги на Енисей в XIX веке: история одного удачного переселения старообрядческого клана // Книжность и старообрядчество Костромского края и сопредельных территорий : сб. науч. ст. / отв. ред. Ю. С. Белянкин. М. : Археодоксія. Т. 2. 140 с. С. 132-139.

Татаринцева, М. П. (2006) Старообрядцы в Туве: историко-этнографический очерк. Новосибирск : Наука. 216 с.

Татаринцева, М. П. (2009) Частушки. Русский фольклор в Туве. Кызыл : Аныяк. 200 с.

Татаринцева, М. П. (2018) Проблема сохранения культурных традиций в изменяющихся условиях (на примере старообрядцев в Туве) // IV Центральноазиатские исторические чтения. Пространство культур: через призму единства и многообразия : сборник материалов Международной научно-практической конференции (г. Кызыл, 20-23 сентября 2018 г.) / отв. ред. 3. Ю. Доржу, В. М. Дамдынчап, Ю. В. Попков, А. А. Стороженко. Кызыл : Изд-во ТувГУ. 350 с. С. $172-177$.

Татаринцева, М. П., Моллеров, Н. М. (2016) Русские в Туве (конец ХIX - первая половина ХХ в.): История. Этнография. Культура. Новосибирск : Наука. 295 с. 


\section{REFERENCES}

Balakina, G. F. and Anaiban Z. V. (1995) Sovremennaia Tuva: sotsiokul'turnye i etnicheskie protsessy [Contemporary Tuva: socio-cultural and ethnic processes]. Novosibirsk, Nauka, Sib. izd. firma. 137 p. (In Russ.).

Balakina, G. F. (1998) Dinamika sotsiokul'turnykh realii v period transformatsii [Dynamics of socio-cultural realities in the period of transformation]. In: Sotsial'no-ekonomicheskie problemy Respubliki Tyva v period transformatsii [Socioeconomic problems of the Republic of Tyva in the period of transformation]: a collection of research articles / ed. by G. F. Balakina. Novosibirsk, Izd-vo SO RAN. 120 p. Pp. 75-84. (In Russ.).

Barth, F. (2006) Vvedenie [Introduction]. In: Etnicheskie gruppy i sotsial'nye granitsy. Sotsial'naia organizatsiia kul'turnykh razlichii [Ethnic groups and social boundaries. The social organization of cultural differences] / ed. by Fredrik Barth. Moscow, Novoe izdatel'stvo. 200 p. Pp. 9-49. (In Russ.).

Belova, O. V. (2005) Etnokul'turnye stereotipy v slavianskoi narodnoi traditsii [Ethnocultural stereotypes in the Slavic folk tradition]. Moscow, Indrik. 288 p. (In Russ.).

Dulov, V. I. (1956) Sotsial'no-ekonomicheskaia istoriia Tuvy. XIX - nachalo XX v. [The socio-economic history of Tuva: 19th - early 20th centuries]. Moscow, Publishing House of the Academy of Sciences of the USSR. 608 p. (In Russ.).

Istoriia Tuvy [The History Of Tuva] (2001) : in 2 vol. 2nd ed / ed. by S. I. Vanshtein and M. Kh. Mannai-ool. Novosibirsk, Nauka. Vol. I. 367 p. (In Russ.).

Katanov, N. F. (2011) Ocherki uriankhaiskoi zemli. Dnevnik puteshestviia, ispolnennogo v 1889 godu [Essays on the Uriankhai Territory. The diary of a journey made in 1889]. Prep., introduction and comm. by A. K. Kuzhuget. Kyzyl, TIGPI pri Pravitel'stve RT. 383 p. (In Russ.).

Kon, F. Ya. (2007) Usinskii krai [Usinskii region]. In: Uriankhai. Tyva depter [Uriankhai. A Tuvan notebook] / comp. by S. K. Shoigu. Moscow, Slovo. Vol. 4. Uriankhaiskii krai: perekrestok mnenii (konets XIX - nachalo XX v.) [Uriankhai Territory: the intersection of opinions (late 19th - early 20th century)]. 549 p. Pp. 262-347. (In Russ.).

Kon, F. Ya. (2007) Ekspeditsiia v Soiotiiu [An Expedition to Soyotia]. In: Uriankhai. Tyva depter [Uriankhai. A Tuvan notebook] / comp. by S. K. Shoigu. Moscow, Slovo. Vol. 4. Uriankhaiskii krai: perekrestok mnenii (konets XIX - nachalo XX v.) [Uriankhai Territory: the intersection of opinions (late 19th - early 20th century)]. 549 p. Pp. 348-548. (In Russ.).

Kurbatskii, G. N. (2001) Tuvintsy v svoem fol'klore (istoriko-etnograficheskie aspekty tuvinskogo fol'klora) [Tuvans in their folklore: Historical and ethnographic aspects of Tuvan folklore)]. Kyzyl, Tuva book publishing house. 464 p. (In Russ.).

Lamazhaa, Ch. K. (2018) Natsional'nyi kharakter tuvintsev [National character of Tuvans]. Moscow, St. Petersburg, Nestor-Istoriia. 240 p. (In Russ.)

Maslov, P. P. (2007) Konets Uriankhaia. Putevye ocherki [The End of Uriankhai: Travel essays]. In: Uriankhai. Tyva depter [Uriankhai: A Tuvan Notebook]: in 7 vols. / comp. by S. K. Shoigu. Moscow, Slovo. Vol. 5. Uriankhaiskii krai: ot Uriankhaia k Tannu-Tuve (konets XIX - pervaia polovina XX v.) [Uriankhai Territory: from Uriankhai to Tannu-Tuva (late XIX - first half of XX century)]. 735 p. Pp. 618-729. (In Russ.).

Mamsik, T. S. (1982) Belovodtsy i Belovod'e (Po materialam sledstvennogo dela o pobege 1827-1828 gg.) [Belovodtsy and Belovodye (from the investigation of the case of great escape of 1827-1828)]. In: Istochniki po kul'ture $i$ klassovoi bor'be feodal'nogo perioda (Arkheografiia i istochnikovedenie Sibiri) [Sources on culture and class struggle of the feudal period: Archeography and source studies of Siberia] / ed. by N. N. Pokrovsky and E. K. Romodanovskaia. Novosibirsk, Nauka. 273 p. Pp. 135-165.

Pokrovsky, N. N. and Zol'nikova, N. D. (2002) Starovery-chasovennye na vostoke Rossii v XVIII-XX vv. : Problemy tvorchestva i obshchestvennogo soznaniia [Old believers of the Chasovennoye accord in the East of Russia in the 18th - 20th centuries: Problems of creativity and public consciousness]. Moscow, Pamiatniki istoricheskoi mysli. 471 p. (In Russ.).

Putilov, N. A. (1885) Usinskii krai [Usinskii region]. Eniseiskie eparkhial'nye vedomosti, no. 1, 5, 9, 12, 16, 19-20. (In Russ.)

Putilov, N. A. (1914) Letopis' Usinskoi missii, nakhodiashcheisia na reke Usu, Eniseiskoi gub., Minusinskogo okruga, Shushenskoi volosti, bliz kitaiskoi granitsy [The chronicle of the Usinskaia mission on the Us River, Yenisei Governorate, Minusinsky district, Shushenskaya volost, near the Chinese border]. In: Sibirskii arkhiv [Siberian Archive]: Journal of History, Archeology, Geography and Ethnography of Siberia, Central Asia and the Far East, no. 1, January, pp. 27-40. (In Russ.)

Radlov, V. V. (1907) Obraztsy narodnoi literatury tiurkskikh plemen [Samples of folk literature of the Turkic tribes]. Part IX. Dialects of the Uriankhai (Soyots), Abakan Tatars and Karagases. Texts collected and translated by N. F. Katanov. St. Petersburg, s. n. 659 p. Pp. 1-216. (In Russ.)

Rodevich, V. M. (2007) Ocherk Uriankhaiskogo kraia [An outline of the Uriankhai Territory]. In: Uriankhai. Tyva depter [Uriankhai. Tyva depter] : in 7 vols. / comp. by S. K. Shoigu. Moscow, Slovo. Vol. 3: Uriankhaiskii krai. Tuvinsko-russkie otnosheniia (nachalo XVII - nachalo XX vv.) [Uriankhai Territory. Tuvan-Russian relations (early 17th - early 20th centuries)]. 608 p. Pp. 342-542. (In Russ.).

Rygovskii, D. S. (2018) «Pravilo chashki»: gostepriimstvo staroobriadtsev v antropologicheskoi perspektive [“The rule of the cup": the hospitality of the Old Believers in an anthropological perspective]. In: IV Tsentral'noaziatskie istoricheskie chteniia. Prostranstvo kul'tur: cherez prizmu edinstva i mnogoobraziia $4^{\text {th }}$ Readings in Central Asian history: The space 
of cultures through the prism of unity and diversity]: Proceedings of an international conference / ed. by Z. Yu. Dorzhu, V. M. Damdynchap, Yu. V. Popkova and A. A. Storozhenko. Kyzyl, TuvSU Publ. 350 p. Pp. 172-177. (In Russ.)

Storozhenko, A. A. (2015) Konfessional'nye migratsii staroobriadtsev kak kanal mezhkul'turnogo vzaimodeistviia v Tsentral'noi Azii v XIX - nachale XX v. [Confessional migrations of Old Believers as a channel of intercultural interaction in Central Asia in the 19th - early 20th centuries]. In: Staroobriadchestvo: istoriia i sovremennost', mestnye traditsii, russkie i zarubezhnye sviazi [Old Belief: history, modernity and local traditions, Russian and foreign relations]: Proceedings of the 6th International research and practical conference / ed. by A. P. Maiorov and S. V. Vasil'eva. Ulan-Ude, Izd-vo Buriatskogo gos. un-ta. 392 p. Pp. 130-136. (In Russ.).

Storozhenko, A. A. (2019a) Staroobriadcheskie monastyri «eniseiskogo meridiana» v XX veke: istoki, traditsii i sovremennoe sostoianie [Old Belief monasteries of the «Yenisei meridian» in the 20th century: origins, traditions and current state]. New Research of Tuva, no. 1, pp. 4-15. (In Russ.). DOI: https://www.doi.org/10.25178/nit.2019.1.1

Storozhenko, A. A. (2019b) S Volgi na Enisei v XIX veke: istoriia odnogo udachnogo pereseleniia staroobriadcheskogo klana [From the Volga to the Yenisei river in the nineteenth century: a story of a successful resettlement of an Old Believer clan]. In: Knizhnost' i staroobriadchestvo Kostromskogo kraia i sopredel'nykh territorii [Book culture and the old believers of Kostroma region and adjacent territories] : a collection of research articles / ed. by Yu. S. Beliankin. Moscow, Arkheodoksiia. Vol. 2. 140 p. Pp. 132-139. (In Russ.).

Tatarintseva, M. P. (2006) Staroobriadtsy v Tuve: istoriko-etnograficheskii ocherk [Old Believers in Tuva: a historical and ethnographic essay]. Novosibirsk, Nauka. 216 p. (In Russ.).

Tatarintseva, M. P. (2009) Chastushki. Russkii fol'klor v Tuve [Chastushki. Russian folklore in Tuva]. Kyzyl, Anyiak. 200 p. (In Russ.).

Tatarintseva, M. P. (2018) Problema sokhraneniia kul'turnykh traditsii v izmeniaiushchikhsia usloviiakh (na primere staroobriadtsev v Tuve) [The problem of preserving cultural traditions in changing conditions: the case of Old Believers in Tuva)]. In: IV Tsentral'noaziatskie istoricheskie chteniia. Prostranstvo kul'tur: cherez prizmu edinstva i raznoobraziia [4th readings in Central Asian history: The space of cultures through the prism of unity and diversity]. Proceedings of an international conference / ed. by Z. Yu. Dorzhu, V. M. Damdynchap, Yu. V. Popkova and A. A. Storozhenko. Kyzyl, TuvSU Publ. 350 p. Pp. 177-181. (In Russ.).

Tatarintseva, M. P. and Mollerov, N. M. (2016) Russkie v Tuve (konets XIX - pervaia polovina XX v.) [Russians in Tuva in late 19th and the first half of 20th centuries]. Novosibirsk, Nauka. 295 p. (In Russ.). 